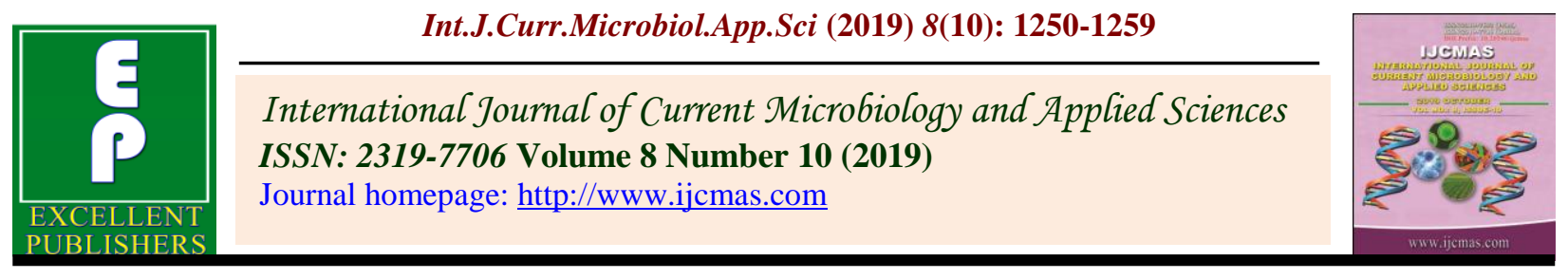

Original Research Article https://doi.org/10.20546/ijcmas.2019.810.147

\title{
Antimicrobial Resistance Profile of Livestock and Poultry of North-Western Punjab
}

\author{
Rinmuanpuii Ralte*, Vipan Kumar, Mohd.Yaqoob Wani, \\ S. N. S. Randhawa, Andleeb Malik and Naripjeet Kaur
}
Department of Veterinary Microbiology, Khalsa College of Veterinary and Animal Sciences, Ram Tirath Road, Amritsar - 143 001, Punjab, India

*Corresponding author

\section{A B S T R A C T}

\section{Keywords}

Antibacterial resistance profile, Livestock, Poultry, Emergence of resistance

\section{Article Info}

\section{Accepted:}

10 September 2019

Available Online:

10 October 2019
Antimicrobial resistance has made its niche in diverse animal pathogens including protozoa especially in emerging and re-emerging zoonotic pathogens, thus act as one of the most formidable enemy of the society. The study was aimed to document the prevailing antibacterial resistance profile of bacterial isolates from clinical samples (uterine discharge, mastitic milk, direct swabs from throat, nasal and ocular infection) of different animal species (bovine, caprine, canine and poultry). The isolated bacteria are Pasteurella, E. coli, Klebsiella, Salmonella, Pseudomonas, Staphylococcus, Streptococcus, Corynebacterium and Bacillus. Resistance to at least one antimicrobial agent was demonstrated in all the isolates and the highest levels of multidrug-resistant strains were obtained from bovine milk followed by cloacal swabs of poultry birds. E.coli was found to be most sensitive to amikacin, ceftazidime and cefotetan; Staphylococcus aureus to piperacillin/tazobactam; Streptococcus $\mathrm{sp}$ to piperacillin/tazobactam, ceftazidime and ticarcillin/clavulanic acid; Pseudomonas and Klebsiella sp to amikacin; and Pasteurella multocida was found to be sensitive to cefotaxime, clindamycin, chloramphenicol and gentamicin. This profile will help in selection of antimicrobials for treatment of animals in the North-Western region of Punjab.

\section{Introduction}

Antibacterial resistance has become one of the most critical public health problems (Davis and Davis, 2010; Cabello et al., 2016; Robinson et al., 2016a). Injudicious use of antimicrobials in the livestock industry, agriculture and biomedicine has resulted in the creation of strong selective resistance to antibiotics (Manyi-Loh et al., 2018). This emergence of resistant bacterial strain is a major problem in animal and human medicine (Wegener et al., 1999; Aslantas and Demir, 2016). Profiling of resistant strains prevailing in Punjab in the livestock sector as well as poultry farms will provide for and mitigate the 
present problem of injudicious use of antibiotics and public health concern. World Health Organization (WHO, 2016) has emphasized the importance of reducing the incidence of bacterial resistance and production losses to the livestock industry in general and public health significance in particular. To achieve this goal, comprehensive documentation of antimicrobial usage and emergence of resistance among humans and animals is necessary.

Antimicrobials are crucial for maintenance of animal health, animal welfare and food-safety (FAO, 2016; Magouras et al., 2017).Recent reports indicated a steady rise in antibiotic resistance globally among the animals as well as humans (Aslam et al., 2018). Resistant bacterial strains of Staphylococcus aureus, E.coli, Salmonella, Klebsiella pneumonia, Campylobacter isolated from cattle, pigs, poultry farms, human hospitals, slaughterhouses, animal handlers, etc are continuously emerging even against higher generation of antibacterials like Quinolones (Zurfluh et al., 2015), Methicillin (Yang et al., 2016), Cephalosporins and many other classes (Gharied et al., 2015; Kashoma et al., 2015; Agabou et al., 2016; Eguale et al., 2016; Lalak et al., 2016; Ibrahim et al., 2016; Papadopoulos et al., 2016; Ranjbar et al., 2016). Under such situations, control of antibiotics use in agricultural farms and livestock industries (Aarestrup, 2015; Vishnuraj et al., 2016; Robinson et al., 2016b), clinics and hospitals (Weinstein, 2001) will play an important role for effective extenuation of the spread of antibiotic resistance.

Antibiogram profile of various bacterial strains present in different ecosystem varies with regards to its geographical location (Sahoo et al., 2012). Detection and documentation of prevalent microbial system with antibiogram profile is expected to contribute as a biological guide to minimize and limit the injudicious use of antimicrobials and non-essential prophylactic substances in the system (WHO, 2013). Our work has been designed to document the antibiotic resistance profile of prevalent bacterial pathogens causing common infections in livestock, companion animals and poultry of NorthWestern Punjab regions.

\section{Materials and Methods}

\section{Sample collection and preparation}

A total of 235 clinical samples from swabs and lesions at different sites (skin scrapes, ocular, nasal and uterine discharges, rectal pinch) mastitic milk and diarrheic samples from cattle, buffalo, sheep, goat, dog and poultry routinely submitted from Veterinary Clinical Complex (VCC) as well as specimens collected separately from the field during the past four years (i.e., years 2014 to 2018) were processed as per standard microbiological protocols.

\section{Microbial isolation and biochemical identification of bacteria}

Samples were individually processed for isolation of bacterial pathogens as per routine bacterial isolation method (Markey et al., 2013). Samples were inoculated into brain heart infusion (BHI) broth and incubated at $37^{\circ} \mathrm{C}$ for $16 \mathrm{hrs}$. Isolation of single colonies was achieved as per routine streaking method into $10 \%$ sheep blood agar and incubated both aerobically and anaerobically in a GasPak system at $37^{\circ} \mathrm{C}$ for $48 \mathrm{hrs}$. Single isolated colonies were stained with routine staining procedure to identify Gram stained characteristic and morphology.

Bacterial colonies were subjected to standard biochemical testing for species identification. 


\section{Antibiogram}

Antimicrobial susceptibility tests were performed using disk diffusion method on Mueller Hinton Agar (MHA) plate following Clinical and Laboratory Standards Institute (CLSI) documents M100-S22 (CLSI, 2019). The following antibiotic discs (HiMedia) were tested-Amoxycillin/Clavulanic acid (100/10mcg, AMC), Ampicillin (AMP), Azithromycin (AZT), Methicillin (MET), Clindamycin (CD), Gentamicin (GEN), Enrofloxacin (\%mcg, E), Ciprofloxacin, Nalidixic acid, Nitrofurantoin, Ertapenem, Cefotetan, Cefotaxime, Ceftazidime, Ticarcillin/Clavulanic acid, Piperacillin/ Tazobactam, Colistin. Isolates resistant to three or more antimicrobial classes are classified as Multi-Drug Resistant strains (MDRs) according to Magiorakos and coworkers (2012).

\section{Results and Discussion}

\section{Microbial isolation and biochemical} identification of bacteria

Major pathogenic organisms isolated from the clinical samples ranges from gram negative bacteria such as E.coli, Salmonella, Klebsiella, Citrobacter, Pseudomonas, Pasteurella and gram positive bacteria such as Staphylococcus, Streptococcus, Corynebacterium and Bacillus as shown in the table 1 .

In mastitic milk samples of dairy animals, Staphylococcus aureus (41.25\%) was found to be most prevalent followed by $E$. coli (30.00\%), Streptococcus sp and Klebsiella sp $(11.25 \%)$.

Staphylococcus,

Pseudomonas, Corynebacterium and Bacillus species are isolated from skin scrapes, throat swabs and ocular swab samples from cows, buffaloes, horses and dogs. Staphylococcus aureus $(43.3 \%)$ was found to be the most prevalent isolates from skin scrapings, followed closely by Pseudomonas and Corynebacterium sp in canines. Staphylococcus pseudintermedius was confirmed as the major isolate from canine skin and ear infection, whereas, Staphylococcus aureus made up the majority of isolates from mastitic milk samples. However throat and ocular swabs showed Corynebacterium (50.0\%) and Staphylococcus sp $(30.0 \%)$ as the major isolates in canine samples, respectively.

In uterine discharge samples of caprine, the most prevalent isolates were E. coli $(28.9 \%)$ and Staphylococcus species (31.1\%). Pasteurella multocida (40.0\%) was isolated from bovine throat swab samples. Salmonella sp. (40.0\%), E.coli (40.0\%) and Klebsiella sp. $(10.0 \%)$ were isolated from cloacal swab samples from a poultry farm with diarrheal outbreak and sudden death.

\section{Antibiogram}

The bacterial isolates from various clinical samples showed resistance to antibiotics as shown in the tables (Table 2 and 3; Fig. 1 and 2). Multi-drug resistance was observed with E.coli isolates. Gram positive Staphylococcus isolates from canine skin infections showed resistance to a majority of the commonly used antibiotics. Other bacterial isolates such as Streptococcus, Corynebacterium, Pasteurella, Klebsiella, and Salmonella showed resistance percentages ranging from $4 \%$ to $50 \%$ against various antibiotics commonly used for treatment of infection in animals.

Resistance to at least one antimicrobial agent was demonstrated in all the isolates and the highest levels of multidrug-resistant strains were obtained from bovine milk followed by poultry rectal swabs. Antibiotic resistance was observed to be very high in isolates of E.coli, Pseudomonas and Staphylococcus sp. E. coli was found to be most sensitive to amikacin, 
ceftazidime and cefotetan; Staphylococcus aureus to piperacillin/ tazobactam; Streptococcus sp to piperacillin/ tazobactam, ceftazidime and ticarcillin/ clavulanic acid; Pseudomonas and Klebsiella sp to amikacin; and Pasteurella multocida was found to be sensitive to cefotaxime, clindamycin, chloramphenicol and gentamicin.

Many of these isolated organisms are commensals of the skin and the digestive tracts. Gram-negative such as E.coli and Pseudomonas aeruginosa formed one of the major isolates from mastitic milk samples. Isolation of coliform bacteria such as E.coli and Klebsiella in milk indicated environmental contamination and unhygienic practice in the farm.

Gram positive bacteria, viz., Staphylococcus and Streptococcus are one of the most common pathogens responsible for mastitis in milch animals and are responsible for huge economic losses of the dairy industry. Isolation of these gram-positive bacteria in milk indicated unhygienic milking practice on the farm. Many isolates are resistant to antibiotics and can be responsible for a serious problem regarding hygienic milk production, animal and public health.

Staphylococcus sp are commensals of the skin and are the major pathogens for bacterial pyoderma, folliculitis and contagious epidermal collarette in dogs.

Pseudomonas sp are opportunistic bacteria and are found in compromised skin lesions such as burns, animals receiving steroid therapy (immunosuppressed/ immunocompromised), chronic ear infection and pododermatitis in conjunction with certain yeasts such as Malassezia sp. In poultry birds, Salmonella sp. is one of the most important pathogens causing acute infections.
The result of the study has shown widespread distribution of antibiotic resistant bacterial strains not only in the livestock, but also that of pet animals in Punjab.

Increase in the distribution of antibiotic resistant bacterial strains in various farm animals and as well as pet animals poses greater challenge for public health with regards to transmission of antibiotic resistant pathogens from farm to farm, animals to humans and vice versa (Kruse, 1999; Guardabassi et al., 2004; Phillips et al., 2004). Due to limitations of antimicrobials used for treatment of pets, commercially available antimicrobials are usually used in veterinary practice, such as antibiotics banned in food animals (eg. chloramphenicol), topical ointment for humans e.g. mupirocin and fusidic acid) and last-line of antimicrobials in human medicine e.g. new generation cephalosporins and fluroquinolones) (Guardabassi et al., 2004). To ameliorate further increase in emergence of new resistant strains, public awareness, farmer - veterinarian interactions and alternative methods of medications and disease control measures like vaccinations need to be encouraged.

Current knowledge on prevalence of antimicrobial resistance, injudicious use of a particular class or type of antibiotics in farm animals, poultry as well as dogs and cats with focus on the potential implications for human health are very much inadequate in Amritsar region.

This compiled data of resistance chart as per samples received from clinics and field can assist in choosing and avoiding the use of a particular antibiotic in a particular region or farm. 
Table.1 Lists of pathogenic microorganisms isolated from clinical samples of buffaloes, cows, sheep, goat, and dogs obtained from TVCC, KCVAS and from field cases

\begin{tabular}{|c|c|c|c|c|}
\hline $\begin{array}{c}\text { Clinical sample } \\
\text { (Total) }\end{array}$ & Species & Micro-organism(s) & $\begin{array}{c}\text { No of positive } \\
\text { samples }\end{array}$ & $\begin{array}{c}\text { Percentage } \\
\text { positivity }(\%)\end{array}$ \\
\hline \multirow{8}{*}{$\begin{array}{c}\text { Mastitic milk } \\
\qquad(80)\end{array}$} & \multirow[t]{8}{*}{ Bovine } & Escherichia coli & 24 & 30 \\
\hline & & Klebsiella sp & 10 & 12.5 \\
\hline & & Citrobacter $s p$ & 4 & 5 \\
\hline & & Bacillus sp & 9 & 11.25 \\
\hline & & Staphylococcus sp & 33 & 41.25 \\
\hline & & Streptococcus sp & 12 & 15 \\
\hline & & Corynebacterium sp & 8 & 10 \\
\hline & & Pseudomonas sp & 2 & 2.5 \\
\hline \multirow{4}{*}{$\begin{array}{c}\text { Skin scrapings } \\
\text { (30) }\end{array}$} & \multirow[t]{4}{*}{ Canine } & Staphylococcus sp & 13 & 43.3 \\
\hline & & Pseudomonas sp & 9 & 30 \\
\hline & & Corynebacterium sp & 8 & 26.6 \\
\hline & & Bacillus & 4 & 13.3 \\
\hline \multirow{3}{*}{$\begin{array}{c}\text { Throat swab } \\
\text { (20) }\end{array}$} & \multirow[t]{3}{*}{ Canine } & Corynebacterium sp & 10 & 50 \\
\hline & & Pasteurella sp & 7 & 35 \\
\hline & & Streptococcus & 7 & 35 \\
\hline \multirow{3}{*}{$\begin{array}{c}\text { Throat swab } \\
\text { (10) }\end{array}$} & \multirow[t]{3}{*}{ Bovine } & Pasteurella sp & 4 & 40 \\
\hline & & Streptococcus & 4 & 40 \\
\hline & & Staphylococcus sp & 3 & 30 \\
\hline \multirow{4}{*}{$\begin{array}{c}\text { Ocular swab } \\
\qquad(20)\end{array}$} & \multirow[t]{4}{*}{ Canine } & Staphylococcus & 6 & 30 \\
\hline & & Streptococcus & 4 & 20 \\
\hline & & Bacillus & 5 & 25 \\
\hline & & Pseudomonas & 4 & 20 \\
\hline \multirow{4}{*}{$\begin{array}{c}\text { Uterine } \\
\text { discharges/deep } \\
\text { vaginal swab } \\
(45)\end{array}$} & \multirow[t]{4}{*}{ Caprine } & Staphylococcus & 14 & 31.1 \\
\hline & & Streptococcus & 4 & 8.9 \\
\hline & & E. coli & 13 & 28.9 \\
\hline & & Pseudomonas & 3 & 6.6 \\
\hline \multirow{3}{*}{$\begin{array}{c}\text { Cloacal swab } \\
(30)\end{array}$} & \multirow[t]{3}{*}{ Poultry } & Salmonella & 12 & 40 \\
\hline & & E. coli & 12 & 40 \\
\hline & & Klebsiella & 3 & 10 \\
\hline
\end{tabular}


Table.2 The number of antibiotic resistant gram negative bacteria observed per isolates (as per CLSI standard)

\begin{tabular}{|c|c|c|c|c|c|c|c|}
\hline Bacteria (=n) & $\begin{array}{l}\text { E.coli } \\
(49)\end{array}$ & $\begin{array}{c}\text { Klebsiella } \\
\text { (13) }\end{array}$ & $\begin{array}{c}\text { Citrobacter } \\
\text { (4) }\end{array}$ & $\begin{array}{c}\text { Salmonella } \\
\text { (12) }\end{array}$ & $\begin{array}{l}\text { Pseudomonas } \\
\text { (18) }\end{array}$ & $\begin{array}{l}\text { Pasteurella } \\
\text { (7) }\end{array}$ & $\begin{array}{c}\text { Corynebactrium } \\
\text { (26) }\end{array}$ \\
\hline MT $5 \mathrm{mcg}$ & $8 / 49$ & $3 / 12$ & - & - & - & $1 / 7$ & - \\
\hline AMP 10mcg & $34 / 45$ & $4 / 13$ & $0 / 4$ & $1 / 2$ & $4 / 15$ & $2 / 7$ & $8 / 24$ \\
\hline C 30mcg & $6 / 48$ & $2 / 13$ & - & - & - & $1 / 7$ & - \\
\hline AZM 15mcg & $7 / 49$ & $2 / 12$ & - & - & - & $3 / 7$ & - \\
\hline TE 30mcg & $28 / 48$ & $6 / 13$ & $1 / 4$ & $1 / 2$ & $9 / 14$ & $5 / 7$ & $5 / 24$ \\
\hline AK 30mcg & $2 / 49$ & $1 / 11$ & - & - & - & $3 / 6$ & - \\
\hline CD $2 \mathrm{mcg}$ & $7 / 48$ & - & - & - & - & $0 / 7$ & - \\
\hline GEN 10mcg & $6 / 49$ & - & - & - & - & $2 / 7$ & - \\
\hline EX 10mcg & $12 / 38$ & $3 / 11$ & $0 / 4$ & $0 / 2$ & $4 / 16$ & $2 / 7$ & $1 / 23$ \\
\hline CIP 5mcg & $17 / 44$ & $3 / 13$ & $1 / 4$ & $1 / 2$ & $5 / 18$ & $1 / 6$ & $2 / 25$ \\
\hline NA 30mcg & $3 / 44$ & - & $0 / 4$ & - & - & $1 / 5$ & - \\
\hline NIT 100mcg & $4 / 40$ & - & $0 / 4$ & - & - & - & - \\
\hline ETP 10mcg & $2 / 39$ & - & - & - & - & - & - \\
\hline CTN30mcg & $5 / 45$ & - & & - & - & - & - \\
\hline CTX 30mcg & $4 / 42$ & - & $1 / 4$ & - & - & $0 / 6$ & - \\
\hline CAZ 30mcg & $6 / 47$ & - & & - & - & $0 / 6$ & - \\
\hline $\begin{array}{c}\text { TCC 75/10 } \\
\text { mcg }\end{array}$ & $2 / 32$ & - & $0 / 4$ & - & - & $0 / 6$ & - \\
\hline PIT 30/6 mcg & $3 / 28$ & - & $0 / 4$ & - & - & - & - \\
\hline CL 10mcg & $4 / 41$ & - & - & - & - & - & - \\
\hline
\end{tabular}

$\mathrm{AK}=$ Amikacin, $\mathrm{AMP}=$ Ampicillin, $\mathrm{AZM}=$ Azithromycin, $\mathrm{CTX}=$ Cefotaxime, $\mathrm{CTN}=$ Cefotetan, $\mathrm{CAZ}=$ Ceftazidime, $\mathrm{C}=$ Chloramphenicol, $\mathrm{CIP}=$ Ciprofloxacin, $\mathrm{CD}=$ Clindamycin, $\mathrm{CL}=$ Colistin, $\mathrm{EX}=$ Enrofloxacin, ETP $=$ Ertapenem, GEN $=$ Gentamicin, $\mathrm{MT}=$ Metronidazole, NA = Nalidixic acid, NIT $=$ Nitrofurantoin, $\mathrm{TCC}=$ Ticarcillin/Clavulanic acid, PIT = Piperacillin/Tazobactam.

Table.3 Percentage of antibiotic-resistance pattern of Gram positive bacterial isolates (as per CLSI standard)

\begin{tabular}{|c|c|c|c|c|c|c|c|c|c|c|c|c|c|}
\hline Bacteria & AM & $\mathbf{A M}$ & $\mathbf{A Z}$ & $\mathbf{M E}$ & $\mathbf{C D}$ & $\mathbf{C}$ & $\mathbf{G E}$ & $\mathbf{C I}$ & $\mathbf{C T}$ & $\mathbf{C T X}$ & $\mathbf{C A}$ & $\mathbf{T C}$ & $\mathbf{P I T}$ \\
\hline $\begin{array}{c}\text { Staphylococcus } \\
\text { (66) }\end{array}$ & 15 & 33 & 24 & 42 & 21 & 23 & 23 & 18 & 23 & 18 & 16 & 12 & 11 \\
\hline Streptococcus (27) & 8 & 23 & 15 & 22 & 8 & 12 & 7 & 8 & 14 & 12 & 11 & 6 & 4 \\
\hline
\end{tabular}

$\mathrm{AMC}=$ Amoxycillin/Clavulanic acid, $\mathrm{AMP}=$ Ampicillin, $\mathrm{AZM}=$ Azithromycin, $\mathrm{MET}=$ Methicillin, $\mathrm{CD}=$ Clindamycin, $\mathrm{C}=$ Chloramphenicol, $\mathrm{GEN}=$ Gentamicin, $\mathrm{CIP}=$ Ciprofloxacin, $\mathrm{CTN}=$ Cefotetan, CTX $=$ Cefotaxime, $\mathrm{CAZ}=$ Ceftazidime, $\mathrm{TCC}=$ Ticarcillin/Clavulanic acid, PIT $=$ Piperacillin/Tazobactam, $\mathrm{CL}=$ Colistin 
Fig.1 Percent antibiotic-resistance of gram negative bacterial isolates against commonly used antibiotics

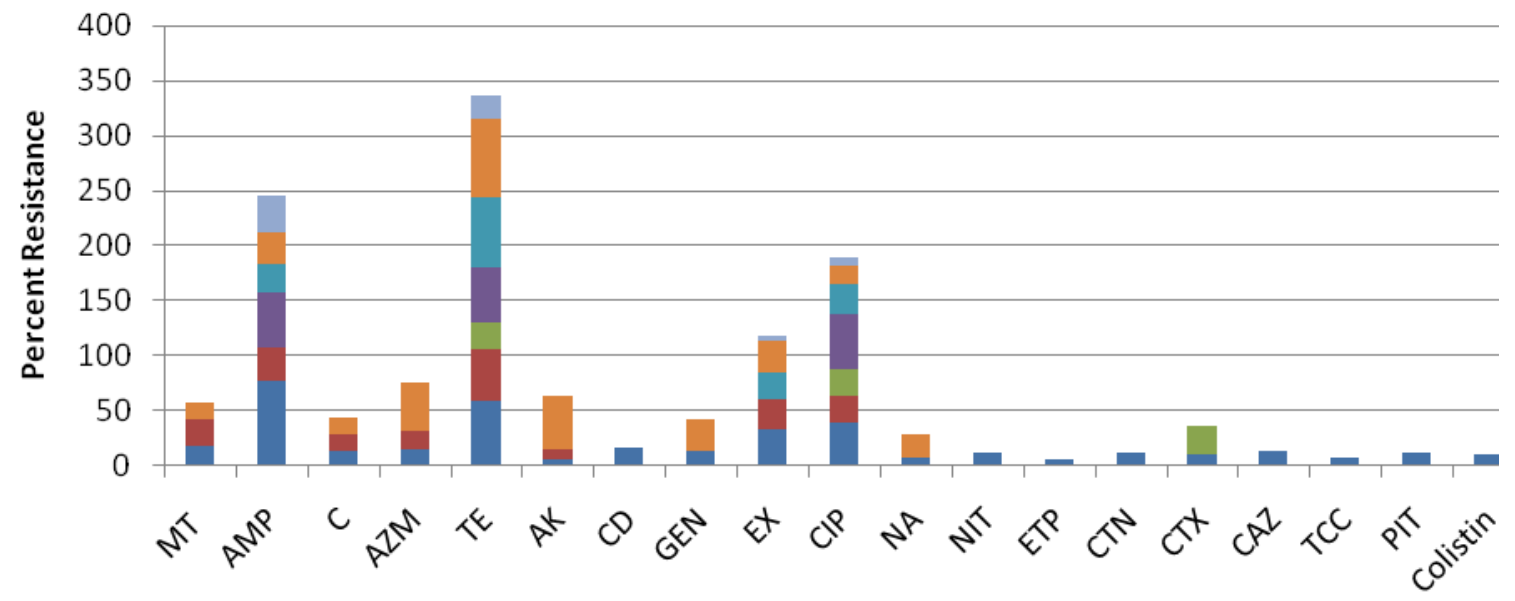

E.coli (49)

- Pseudomonas (18)
- Klebsiella (13)

- Pasteurella (7)
Antibiotics

Citrobacter (4)
Corynebactrium (26)

$\mathrm{AK}=$ Amikacin, $\mathrm{AMP}=$ Ampicillin, $\mathrm{AZM}=$ Azithromycin, $\mathrm{CTX}=$ Cefotaxime, $\mathrm{CTN}=$ Cefotetan, $\mathrm{CAZ}=$ Ceftazidime, $\mathrm{C}=$ Chloramphenicol, $\mathrm{CIP}=$ Ciprofloxacin, $\mathrm{CD}=$ Clindamycin, $\mathrm{CL}=$ Colistin, EX $=$ Enrofloxacin, ETP $=$ Ertapenem, GEN $=$ Gentamicin, $\mathrm{MT}=$ Metronidazole, NA = Nalidixic acid, NIT $=$ Nitrofurantoin, TCC $=$ Ticarcillin/Clavulanic acid, PIT $=$ Piperacillin/Tazobactam .

Fig.2 Percent antibiotic-resistance of Staphylococcus sp. and Streptococcus sp. against commonly used antibiotics

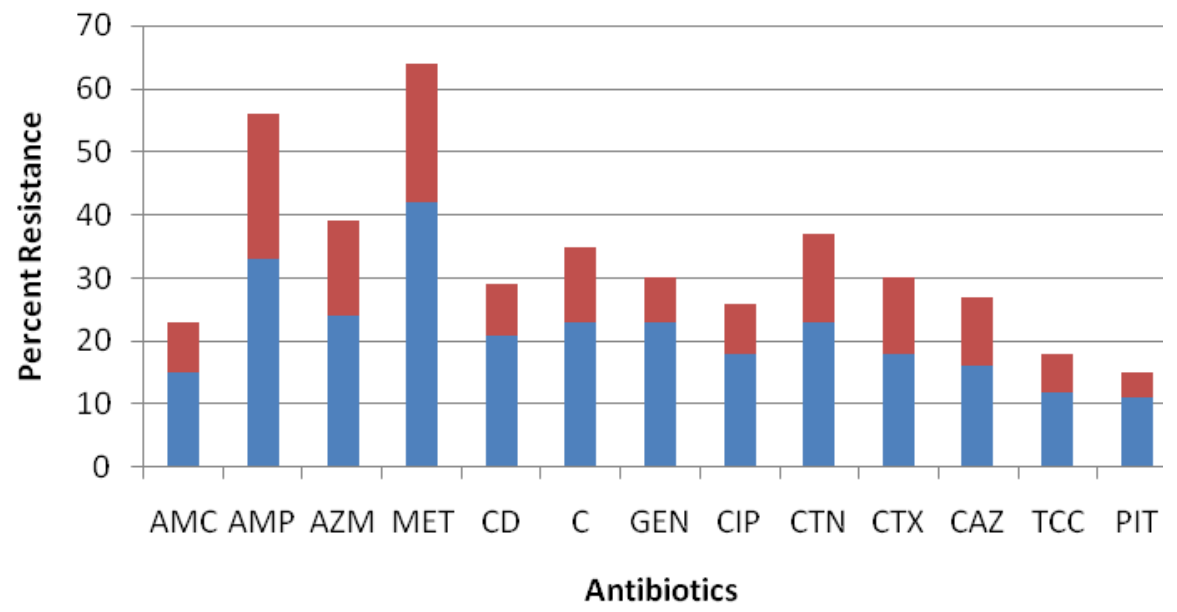

- Staphylococcus $\quad$ Streptococcus

$\mathrm{AMC}=$ Amoxycillin/Clavulanic acid, $\mathrm{AMP}=$ Ampicillin, $\mathrm{AZM}=$ Azithromycin, $\mathrm{MET}=$ Methicillin, $\mathrm{CD}=$ Clindamycin, $\mathrm{C}=$ Chloramphenicol, $\mathrm{GEN}=$ Gentamicin, $\mathrm{CIP}=$ Ciprofloxacin, $\mathrm{CTN}=$ Cefotetan, $\mathrm{CTX}=$ Cefotaxime, $\mathrm{CAZ}=$ Ceftazidime, $\mathrm{TCC}=$ Ticarcillin/Clavulanic acid, $\mathrm{PIT}=$ Piperacillin/Tazobactam, $\mathrm{CL}=$ Colistin . 
Adoption of appropriate and timely measures like proper drug sensitivity tests, rotational and differential usage of antibiotics and avoidance of continuous and excessive use of specific antibacterial agents for a particular pathogen. Such measures will have long lasting beneficial and economic effects for animal health in general and food safety and public health significance in particular.

\section{Conflict of Interest}

The authors declare that there is no conflict of interest to disclose regarding the research work presented here.

\section{Acknowledgement}

The authors are grateful to the Principal, Khalsa College of Veterinary and Animal Sciences, Amritsar, for providing the necessary facilities and financial support for the study.

\section{References}

Aarestrup, F.M (2015). The livestock reservoir for antimicrobial resistance: A personal view on changing patterns of risks, effects of interventions and the way forward. Philos Trans $R$ Soc Lond B Biol Sci. 370(1650): 20140085. doi: 10.1098/rstb.2014.0085.

Agabou, A., Lezzar, N., Ouchenane, Z., Khemissi, S., Satta, D., Sotto, A., Lavigne, J.P., Pantel, A. (2016). Clonal relationship between human and avian ciprofloxacin-resistant Escherichia coli isolates in North-Eastern Algeria. Eur J Clin. Microbiol. Infect. Dis., 35(2):227234. doi: 10.1007/s10096-015-2534-3.

Aslam, B., Wang, W., Arshad, M.I., Khurshid, M., Muzammil, S., Rasool, M.H., Nisar, M.A., Alvi, R.F. and Aslam, M.A. (2018). Antibiotic resistance: a rundown of a global crisis. Infect Drug Resist 11: 1645-1658. doi: 10.2147/IDR.S173867.
Aslantaş, Ö. And Demir, C. (2016). Investigation of the antibiotic resistance and biofilm-forming ability of Staphylococcus aureus from subclinical bovine mastitis cases. J. Dairy Sci. 99(11):8607-8613.

doi: 10.3168/jds.2016-11310.

Cabello F.C. and Godfrey, H.P (2016). Even therapeutic antimicrobial use in animal husbandry may generate environmental hazards to human health. Environ Microbiol. 182: 311-313. doi: 10.1111/1462-2920.13247.

Clinical and Laboratory Standards Institute (CLSI) (2019). Performance Standards for Antimicrobial Susceptibility Testing. $29^{\text {th }}$ ed. CLSI supplement M100 (ISBN 978-1-68440-032-4 [Print]; ISBN 978-168440-033-1 [Electronic]. Clinical and Laboratory Standards Institutes, 950 West Valley Road, Suite 2500, Wayne, Pennsylvania 19087 USA,.

Davies, J and Davies, D (2010). Origins and evolutions of antibiotic resistance. Microbiol. Mol. Biol. Rev. 74:417

Eguale, T., Engidawork, E., Gebreyes, W.A., Astrat, D., Alemayehu, H., Medhin, G., Johnson, R.P and Gunn, J.S (2016). Fecal prevalence, serotype distribution and antimicrobial resistance of Salmonellae in dairy cattle in central Ethiopia. BMC Microbiol. 16(1): 20 doi: 10.1186/s12866-016-0638-2.

FAO (2016). Supporting the food and agricultural sectors in implementing the global action plan on antimicrobial resistance to minimize the impact of antimicrobial resistance. The FAO action plan on antimicrobial resistance 2016 - 2020. Food and Agriculture Organization of the United Nations, Rome.

Guardabassi, L., Schwarz, S. and Lloyd D.H. (2004). Pet animals as reservoirs of antimicrobial-resistant bacteria. $J$ Antimicrobial Chemotherapy 54: 321332

Gharieb, R.M., Tartor, Y.H. and Khedr, M.H (2015). Non-typhoidal Salmonella in 
poultry meat and diarrhoeic patients: prevalence, antibiogram, virulotyping, molecular detection and sequencing of class I integrons in multidrug resistant strains. Gut Pathol. 23; 7:34. doi: 10.1186/s13099-015-0081-1. eCollection.

Ibrahim, D.R., Dodd, C.E., Stekel, D.J., Ramsden, S.J. and Hobman, J.L (2016). Multidrug and extended spectrum betalactamase resistant Escherichia coli isolated from a dairy farm. FEMS Microbiol Ecol 92(4):fiw013. doi: 1093/femsec/fiw013.

Kashoma, I.P., Kassem, I.I., Kumar, A., Kessy, B.M., Gebreyes, W., Kazwala, R.R. and Rajashekara, G (2015). Antimicrobial resistance and genotypic diversity of Campylobacteria isolated from pigs, dairy and beef cattle in Tanzania. Front Microbiol 2; 6: 1240. doi: 10.3389/ fmicb.

Kruse, H.(1999). Indirect transfer of antibiotic resistance genes to man. Acta Veterinaria Scandinavia. Supplementum92: 59-65.

Lalak, A., Wasyl, D., Zajac, M., Skarzynska, M., Hoszowski, A., Samcik, I., Wozniakowski, G and Szulowski, K (2016). Mechanism of cephalosporin resistance in indicator in Escherichia coli isolated from food animals. Vet Microbiol. 78-1135(16)30023-2. doi: 10.1016/j.

Magiorakos, A.P., Srinivasan, A., Carey, R.B., Carmelli, Y., Falagas, M.E., Giske, C.G., Harbarth, S., Hindler, J.F., Kahlmeter, G., Olsson-Liljequist, B., Paterson, D.L., Rice, L.B., Stelling, J., Struelens, M.J., Vatopoulos, A., Weber, J.T. and Monnet, D.L. (2012). Multidrug-resistant, extensively drugresistant and pan drug-resistant bacteria: an international expert proposal for interim standard definitions for acquired resistance. Clin Microbiol Infect 18(3): 268-81. doi: 10.1111/j.14690691.2011.03570.x.
Magouras, I., Carmo. L.P., Stärk, K.D.C. and Schupbäch-Regula, G. (2017). Antimicrobial usage and resistance in Livestock: where should we focus? Front. Vet. Sci.4: 148. doi: 10.3389/fvets.2017.00148.

Manyi-Loh, C., Mamphweli, S., Meyer, E and Okoh, A (2018). Antibiotic use in agriculture and its consequential resistance in environmental sources: potential public health implications. Molecules 23:795. doi: 10.3390/molecules23040795.

Markey, B., Leonard, F., Archambault, M., Cullinane, A. and Maguire, D (2013). Clinical Veterinary Microbiology, $2^{\text {nd }}$ Ed,. Mosby Elsevier Ltd.

Papadopoulos, T., Petridou, E., Zdragas, A., Mandilara, G., Nair, S., Peters, T., Chattaway, M., de Pinna E., Passiotou, M. and Vatopoulos, A. (2016). Comparative study of al Salmonella enterica serovar Enteritidis strains isolated from food and food animals in Greece from 2008 to 2010 with clinical isolates. Eur J. ClinMicrobiol Infect Dis. 35(5):741-746 doi: 10.1007/s10096-0162591-2.

Phillips, I., Casewell, M., Cox, T. et al., (2004). Does the use of antibiotics in food animals pose a risk to human health? A critical review of published data. $J$. Antimicrobial Chemotherapy 53: 28-52.

Ranjbar, R., Izadi, M., Hafshejani, T.T., Khamesipour, F (2016). Molecular detection and antimicrobial resistance of Klebsiella pneumonia from house flies (Musca domestica) in kitchens, farms, hospitals and slaughterhouses. J. Infect Public Health. Pii: S18760341(16)00003-4. doi: 10.1016/

Robinson, T.P., Bu, D.P., Carrique-Mas, J., Fèvre, E.M., Gilbert, M., Grace, D., Hay, S.I., Jiwakanon, J., Kakkar, M., Kariuki, S., Laxminarayan, R., Lubroth, J., Magnusson, U., Thi Ngoc, P., Van Boeckel, T.P. and Woolhouse, M.E. (2016a). Antibiotic resistance is the 
quintessential One Health issue. Trans $R$ Soc Trop Med Hyg. 110: 377-380.

Robinson, T.P., Bu, D.P., Carrique-Mas, J., Fèvre, E.M., Gilbert, M., Grace, D., Hay, S.I., Jiwakanon, J., Kakkar, M., Kariuki, S., Laxminarayan, R., Lubroth, J., Magnusson, U., Thin Ngoc, P., Van Boeckel, T.P. and Woolhouse, M.E. (2016b). Animal 11(1):1-3. doi: 10.1017/S1751731116001828.

Sahoo, K.C., Tamhankar, A.J., Sahoo, S., Sahu, P.S., Klintz, S.R., Lindborg, C.S. (2012). Geographical Variation in AntibioticResistant Escherichia coli Isolates from Stool, Cow-Dung and Drinking Water. Int. J. Environ. Res. Public Health 9:746-759.

Vishnuraj, M.R., Kandeepan, G., Rao, K.H., Chand, S and Kumbhar, V (2016). Occurrence public health hazards and detection methods of antibiotic residues in foods of animal origin: a comprehensive review. Cogent Food Agri. 2, 1235458.

Wegener, H.C., Aestrup, F.M., Gerner-Smidt, P. et al., (1999). Transfer of antibiotic resistant bacteria from animals to man. Acta Veterinaria Scandinavica. Supplementum 92: $51-57$.

Weinstein, R.A. (2001). Controlling Antimicrobial Resistance in Hospitals:
Infection Control and Use of Antibiotics. Emerging Infectious Diseases. 7(2):188192. doi:10.3201/eid0702.700188.

World Health Organization (2001). WHO strategy for containment of Antimicrobial resistance. WHO/CDS/CSR/DRS/2001.2.

World Health organization (2011). Step-by-step approach for development and implementation of hospital antibiotic policy and standard treatment guidelines. World Health Organization, Regional Office for South-East Asia, Indraprastha Estate, Mahatma Gandhi Marg, New Delhi-110 002, India. SEAHLM-414.

Yang, X., Zhang, J., Yu, S., Wu, Q., Guo, W., Huang, J. and Cai, S. (2016). Prevalence of Staphylococcus aureus and methicillin-resistant Staphylococcus aureus in retail ready-to-eat foods in China. Front Microbiol. 7:816. doi:10.3389/fmicb.2016.00816.

Zurfluh, K., Cernela, N. and Stephan, R. (2015). Quinolone resistance mechanisms among extended-spectrum betalactamase (ESBL)-producing Escherichia coli isolated from farm animals in Switzerland. Schweiz Arch Tierheilkd 157(1): 59-62.

\section{How to cite this article:}

Rinmuanpuii Ralte, Vipan Kumar, Mohd.Yaqoob Wani, S. N. S. Randhawa, Andleeb Malik and Naripjeet Kaur. 2019. Antimicrobial Resistance Profile of Livestock and Poultry of NorthWestern Punjab. Int.J.Curr.Microbiol.App.Sci. 8(10): 1250-1259. doi: https://doi.org/10.20546/ijcmas.2019.810.147 